Research Article

\title{
A Comparative Study of Functional Properties of Pectin Isolated from Different Fruit and Vegetable Sources
}

\author{
Sumita Dasgupta*, Aneri Shah \\ Biotechnology Department, Bhagwan Mahavir College of Science and Technology, New City Raod, Surat, India. \\ *Corresponding author's E-mail: sumitarup@gmail.com
}

Received: 21-07-2020; Revised: 16-09-2020; Accepted: 28-09-2020; Published on: 20-10-2020.

\begin{abstract}
Pectin is a structural heteropolysaccharide contained in the primary cell walls of terrestrial plants. It is used in food as a gelling agent, particularly in jams and jellies. It is also used in fillings, medicines, sweets, as a stabilizer in fruit juices and milk drinks, and as a source of dietary fibre. Commercial pectin is mostly extracted from fruit sources like apple pomace and peels of citrus fruits. The current study was conducted to extract pectin from pomace of easily available vegetables like carrot (Daucus carota subsp. sativus), French bean (Phaseolus vulgaris) potato (Solanum tuberosum L.) and to compare the physiochemical characteristics of the extracted pectin with that extracted from pomace of apple (Malus domestica) and peels of citrus fruits like lemon (Citrus limon) and citron (Citrus medica). The extracted pectin was characterized extensively in terms of solubility, colour and quantitatively in terms of Yield, Equivalent Weight, Methoxyl Content, Anhydrouronic Acid content (AUA). The product was compared with pure pectin powder using technique of Thin Layer Chromatography (TLC). With the exception of potato all the other sources yielded appreciable amount of pectin. The highest yield (30.18\%) was obtained from citron. The best quality gel was also formed from this pectin isolated from citron. All the extracted crude pectin showed significant Methoxyl content, Anhydrouronic content and degree of esterification. The TLC profile of the extracted pectin was found to be matching with pure pectin.
\end{abstract}

Keywords: Pectin, Methoxyl content, Anhydrouronic content, Esterification.

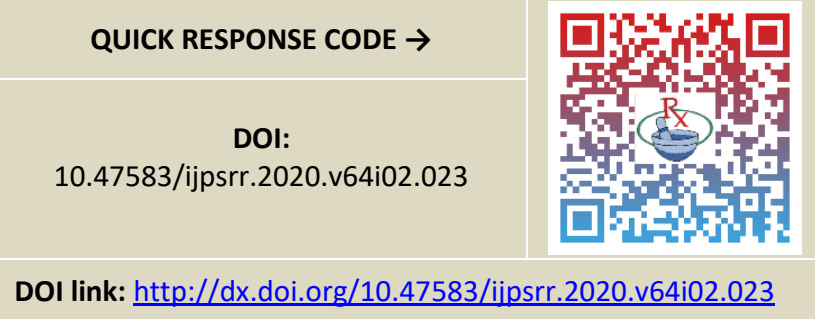

\section{INTRODUCTION}

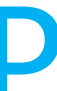

ectin is a complex mixture of polysaccharides occurring in the primary cell wall of terrestrial plant and is a high value functional food ingredient. ${ }^{1}$ Pectin forms gels when dissolved in water under suitable conditions. It is derived from the protopectin found in the middle lamellae of plant cells. Protopectin is insoluble but is converted to soluble pectin as fruit ripens or is heated in an acid medium. ${ }^{2}$ Pectin is widely used in the food industry as a thickener, emulsifier, texturizer and stabilizer. Pectin is usually used in jams and jellies as a gelling agent and also used for fruit preparations, fruit drink concentrates, fruit juice, desserts and fermented dairy products. ${ }^{3}$

In addition, pectin has been shown to lower blood cholesterol levels especially low-density lipoprotein cholesterol fractions and reduces the risk for coronary heart diseases. ${ }^{4}$ The gelling properties of pectin have been known for centuries, but the isolation of commercial pectin only started at the beginning of the twentieth century. ${ }^{5}$ The common raw material for Commercial pectin is apple pomace or citrus peel. ${ }^{6}$ It is now required that alternative sources of Pectin must be investigated to meet the increasing demand. In recent years the production of fruits and vegetables has been increased. Therefore, large amount of fruits and vegetables could be used value added products as well as good source of pectin. ${ }^{3}$

In the present study easily available vegetable sources like carrot (Daucus carota subsp. sativus), French bean (Phaseolus vulgaris) and potato (Solanum tuberosum L.) were explored for pectin extraction and functional properties of pectin extracted from these sources were compared with that isolated from pomace of apple (Malus domestica) and peels of citrus fruits like lemon (Citrus limon) and citron (Citrus medica).

\section{MATERIALS AND METHODS}

\section{Preparation of Extracts}

All sources were washed carefully with tap water to remove dirt soil from surface. The peels of lemon and citron were removed, then cut into smaller pieces, shade dried, and ground to a consistency intermediate to coarse and fine and stored at ambient temperature for further use. For apple, carrot and French bean entire materials were crushed in grinder and the juice was pressed out. The pulpy pomace is used for extraction of pectin.

The pectin extraction process was carried out at different $\mathrm{pH}$ values ranging from $1.2-4.2{ }^{1}$

\section{Extraction using citrus Peels. ${ }^{1}$}

A dry mass of $100 \mathrm{~g}$ peel powder was subjected to extraction by adding $1600 \mathrm{~mL}$ of distilled water followed by $64 \mathrm{~g}$ of citric acid. The mixture was then heated at 
temperatures of $40-90^{\circ} \mathrm{C}$ and continuously stirred for 1 hour, filtered through a whatman No. 1 filter paper or muslin cloth, filtrate was coagulated using an equal volume of $95 \%$ ethanol and left for $2 \mathrm{~h}$ to allow the pectin to float on the surface. The gelatinous pectin flocculants were then skimmed off, filtered and washed 2 - 3 times with ethyl alcohol and finally, the precipitate was dried at $35-40^{\circ} \mathrm{C}$ in hot air oven and then grinded the extraction, the yield was in powder form. The yield was calculated.

\section{Extraction using pomace. ${ }^{7}$}

The pre-treatment such as blanching (boiling at $95^{\circ} \mathrm{C}$ for 5 minutes followed by cooling) and drying in mechanical by oven at $40 \pm 2^{\circ} \mathrm{C}$ was used for extraction of pectin. Method for extraction of pectin consisted of boiling the pomace in distilled water, $0.05 \mathrm{~N} \mathrm{HCL}$ and $0.75 \%$ ammonium oxalateoxalic acid (1:1) for 1 hour at $95^{\circ} \mathrm{C}$. Ratio of $1: 2$ of apple pomace to extraction media was used for extraction. After extraction, the extract was separated from the solid residue by filtration through a muslin cloth prior to its use for pectin precipitation. Liquid pectin extraction was used for the precipitation either with $95 \%$ ethanol or by using Aluminum chloride. The precipitate were then separated, washed successively with 70 and $95 \%$ ethanol, dried in oven at $50^{\circ} \mathrm{C}$, grinded to powder form of Pectin. The yield of dried pectin was calculated and the pectin is stored in ambient temperature for further use.

\section{Identification test of Pectin by Thin Layer Chromatography (TLC). ${ }^{8}$}

$10 \mathrm{ul}$ of sample was loaded on pre-coated silica gel $60 \mathrm{~F}$ 254 aluminium plate and developed in the using suitable solvent system under appropriate condition. TLC Separation was performed for the pectin extracted from apples, carrots, French beans, lemon peels and citron peels. Standard Pectin (procured from Hi-media) was taken as reference. The Solvent system used were Butanol: Formic acid: water (2:3:1, 3:2:1 v/v), Butanol: Water: Acetic acid (2:3:1, 3:2:1 V/V). lodine chamber was used for detection of spot. Rf values were determined after the appearance of spots.

\section{Qualitative Characterization of Pectin ${ }^{9}$}

\section{Stiff gel Test}

$1 \mathrm{~g}$ of pectin was heated with $9 \mathrm{ml}$ of water on a water bath till a solution was formed, on cooling stiff gel was formed.

\section{Test with 95\% Ethanol}

On adding an equal volume of Ethanol (95\%) to $1 \% \mathrm{w} / \mathrm{v}$ solution of pectin sample, a translucent, gelatinous precipitate was produced.

\section{Test with Potassium Hydroxide (KOH)}

To $5 \mathrm{ml}$ of a $1 \% \mathrm{w} / \mathrm{v}$ solution of pectin sample, $1 \mathrm{ml}$ of a $2 \%$ $\mathrm{w} / \mathrm{v}$ solution of $\mathrm{KOH}$ was added and set aside for 15 minutes. A transparent semigel is produced when the above gel was acidified with dilute $\mathrm{HCl}$ and shaken well, a voluminous, colourless gelatinous precipitate forms which upon boiling became white and flocculent.

\section{lodine test}

To $5 \mathrm{ml}$ of recently boiled and cooled $2 \% \mathrm{w} / \mathrm{v}$ solution of sample, $0.15 \mathrm{ml}$ of lodine solution was added. Absence of blue colour gives positive test.

\section{The Quantitative Characterization of Pectin ${ }^{1}$}

\section{Pectin Yield}

The precipitate was dried at $40^{\circ} \mathrm{C}$ in hot air oven and percentage yield was calculated.

$\operatorname{Ypec}(\%)=\mathrm{P} / \mathrm{Bi} \times 100$

Where, Ypec is the yield of pectin in (\%), $\mathrm{P}$ is the amount of extracted pectin in $\mathrm{g}$ and $\mathrm{Bi}$ is the initial amount of pomace or peel powder.

\section{Equivalent Weight ${ }^{10}$}

Pectin sample $(0.5 \mathrm{~g})$ was weighed into $250 \mathrm{ml}$ conical flask and moistened with $5 \mathrm{ml}$ ethanol. A $1.0 \mathrm{~g} \mathrm{NaCl}$ was added to the mixture followed by $100 \mathrm{ml}$ distilled water and 6 drops of phenol red indicator.

Titrated with $0.1 \mathrm{M} \mathrm{NaOH}$ to an end point where pink colour is obtained. This neutralized solution was stored for determination of methoxyl content.

Equivalent weight $=\underline{\text { Weight of sample }(\mathrm{g}) \times 1000}$ Volume of alkali $\times$ Normality of alkali

\section{Methoxyl Content (MeO) ${ }^{10}$}

This was done using the neutralized solution from equivalent weight determination, by the saponification of pectin followed by titration of the liberated acid. $25 \mathrm{ml}$ of $0.25 \mathrm{M} \mathrm{NaOH}$ was added to neutralize solution and the mixture was stirred thoroughly and allowed to stand for 30 $\min$ at room temperature.

A $25 \mathrm{ml}$ of $0.25 \mathrm{~N} \mathrm{HCL}$ was added and titrated with $0.1 \mathrm{~N}$ $\mathrm{NaOH}$. The same end point observed as earlier.

Methoxyl Content $\%=\underline{\text { Volume of alkali } \times \text { Normality of Alkali } \times 3 L \times 100}$

Weight of sample pectin

\section{Anhydrouronic Acid content (AUA) ${ }^{10}$}

The alkali milli-equivalents from equivalent weight, methoxyl content, and alkalinity of ash were taken to calculate anhydrouronic acid (AUA) content. 
Anhydrouronic Acid content $=\underline{176 \text { (m.e. for free acid }+ \text { m.e. for saponification }+ \text { m.e.for titrable ash) } \times 100}$

Weight of the sample (mg)

m.e. =milli-equivalents of alkali

\section{Degree of Esterification (DE) ${ }^{7}$}

The DE of extracted pectin calculated from methoxyl and anhydrouronic acid content using the following expression.

$$
\mathrm{DE} \%=\underline{176 \times \mathrm{MeO}(\%) \times 100}
$$

$$
31 \times A \cup A(\%)
$$

Moisture Content and Ash Content was estimated as per guidelines of Association of Analytical Chemists (AOAC 1995) $)^{11}$ and (AOAC 1975)..$^{12}$

\section{RESULTS AND DISCUSSION}

All the sources except for potato pomace were found to be excellent source of pectin (Fig.1). The $\mathrm{pH}$ determination for maximum pectin yield were found to be for apple 3.6, lemon 4.1, carrot 3.8, citron 4.3 and French bean 4.0 which is in agreement with previous report of instability of pectin under alkaline condition. ${ }^{13}$
Maximum yield under optimum $\mathrm{pH}$ condition as mentioned in Table 1 was obtained from citron (30.18\%) followed by lemon (18.75\%), apple (16.12\%), carrot (14.61\%) and French bean (12.15\%) whereas, in a previous work, amount of pectin obtained from citron, lemon, apple and carrot under optimum condition was $65 \%,{ }^{14}$ $17.36 \%,{ }^{15} 20.60 \%{ }^{8}$ and $15.6 \%{ }^{16}$ respectively.

There is no previous data of pectin extraction from French bean. Preliminary qualitative identification of the isolated Pectin was performed via TLC by co-chromatography technique using Standard Pectin as reference. Of all the solvent system used the system comprising of Butanol: Water: Acetic acid ( 3:2:1) was found to be the best. The $\mathrm{R}_{\mathrm{f}}$ value of all pectin was in range of 0.61-0.62 ( Fig. 2; Table 2) and was found to be matching with that of Standard pectin $\left(R_{f} 0.63\right)$ The result is in agreement with previous work carried out on pectin extracted from Apple and Citrus Pomace. $^{8}$

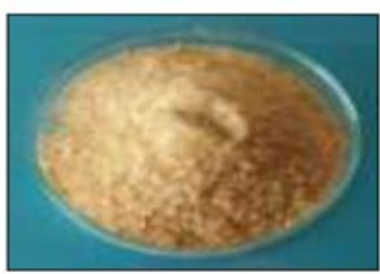

Fig. 1a

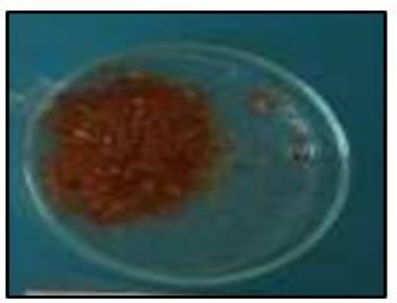

Fig. 1d

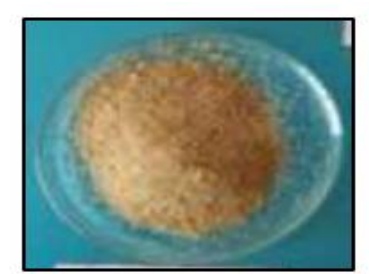

Fig. 1b

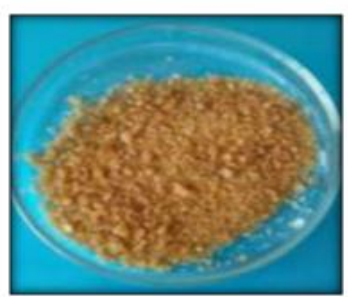

Fig.1e

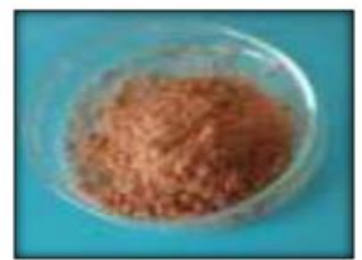

Fig. 1c

Figure 1: Yield of pectin in powder form;

Figure 1a: citron, Figure 1b: lemon, Figure 1c: carrot, Figure 1d: apple, Figure 1e: French bean

Table 1: Percentage (\%) Pectin Yield

\begin{tabular}{|c|c|c|}
\hline Sr.no. & Pectin Source & Pectin Yield (\%) \\
\hline 1 & Apple & $16.12 \pm 0.15$ \\
\hline 2 & Lemon & $18.75 \pm 0.22$ \\
\hline 3 & Carrot & $14.61 \pm 0.34$ \\
\hline 4 & Citron & $30.18 \pm 0.45$ \\
\hline 5 & French Bean & $12.15 \pm 0.70$ \\
\hline
\end{tabular}

The values represent mean of three replicates \pm Standard deviation

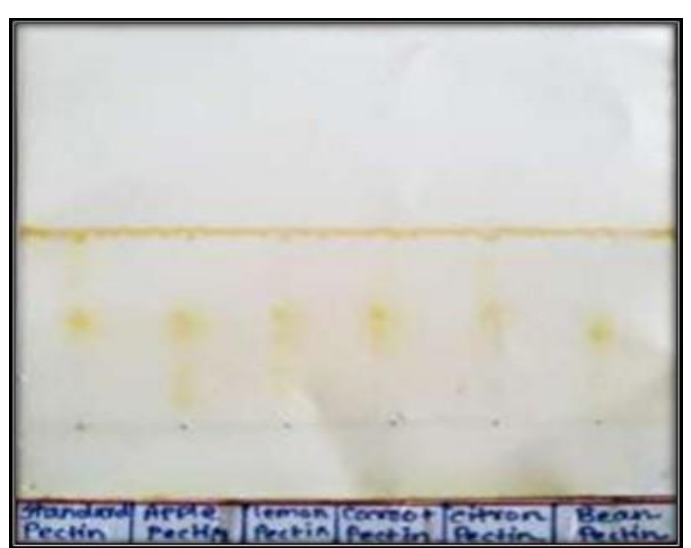

Figure 2: TLC profile of extracted pectin with reference to that of standard pectin 
Table 2: $R_{f}$ values of pectin extracted from different sources

\begin{tabular}{|c|c|c|}
\hline Sr.no. & Pectin Source & $\mathrm{R}_{\mathrm{f}}$ Value \\
\hline 1 & Standard Pectin & 0.63 \\
\hline 2 & Apple & 0.62 \\
\hline 3 & lemon & 0.62 \\
\hline 4 & Carrot & 0.62 \\
\hline 5 & Citron & 0.62 \\
\hline 6 & French Bean & 0.61 \\
\hline
\end{tabular}

Characteristic Variation was observed among the pectin gel obtained from the different sources. Apple, lemon, citron and French bean form stiff gel, whereas carrot formed gelatinous liquid. Ethanol, $\mathrm{KOH}$ and lodine test showed positive result with all the pectin samples (Table 3).

The equivalent weight was found to be highest for pectin obtained from citron and least for the pectin obtained from carrot (Table 4). Equivalent weight of pectin is the total content of free galacturonic acid (not esterified) in the molecular chains of pectin. ${ }^{10}$

Table 3: Qualitative tests of Pectin

\begin{tabular}{|c|c|c|c|c|c|c|}
\hline \multirow{2}{*}{ Sr. No. } & \multirow{2}{*}{ Methods } & \multicolumn{5}{|c|}{ Source } \\
\hline & & Apple & Lemon & Carrot & Citron & French Bean \\
\hline 2 & Ethonol $(95 \%)$ test & + & + & + & + & + \\
\hline 4 & lodine test & + & + & + & + & + \\
\hline
\end{tabular}

Methoxyl content is an important factor in controlling the setting time of pectins and the ability of the pectin to form gels. ${ }^{17}$ In the current study, the methoxyl content varied from $2.3 \%$ to $6.8 \%$ (Table 4 ).

The methoxyl content of pectin usually varies from $0.2-$ $12 \%$ depending on the source and mode of extraction. The values exhibited that the isolated pectin are within the preferred range as also reported in a previous work. ${ }^{1}$

The Degree of Esterification (DE) is the ratio of the esterified galactouronic acid groups to the total galactouronic acid groups present. It is an important property which determines the gelling nature of pectin. ${ }^{18}$

In the present investigation the highest DE value (Table 4) was observed in citron (74.64\%) followed by apple (68.74\%). The pectin obtained from these two sources are catagorized as High methoxyl pectin (HMP) as their DE value is higher than $50 \%$. Pectin obtained from lemon, carrot and French bean fall under the category of low methoxyl (LM) pectins as their DE value is less than $50 \%{ }^{19}$ However in another report it has been stated that $D E$ value of LM-pectins range from 20 to $40 \%$. ${ }^{20}$ So accordingly lemon and French bean with DE value of $42.80 \%$ and $41.72 \%$ can also be considered as High methoxyl pectin.

Anhydrouronic acid content of pectin is an important parameter which indicates the suitability of pectin for its use in jams, jellies etc. ${ }^{21}$ The content of anhydrouronic acid (AUA) indicates the purity of the extracted pectin with a recommended value of not less than $65 \%{ }^{22}$ Results of this study (Table 4) showed that the pectin obtained from all the sources can be considered to be falling within the purity range in terms of Anhydrouronic acid content with pectin extracted from French bean showing the maximum value of $80.95 \%$. The percentage moisture content obtained from the five sources was 58.72, 75.80, 82.70, 66.60 and $80.95 \%$ respectively (Table 4 ).

Table 4: Physico-Chemical Characteristics of extracted Pectin

\begin{tabular}{|c|c|c|c|c|c|}
\hline Parameters & \multicolumn{5}{|c|}{ Pectin Source } \\
\hline & Apple & Lemon & Carrot & Citron & French beans \\
\hline Equivalent Weight (mg/mL) & 594.86 & 386.45 & 253.70 & 694.44 & 293.60 \\
\hline Methoxyl Content (\%) & 6.840 & 4.460 & 2.348 & 4.460 & 3.900 \\
\hline Anhydrouronic Acid Content (\%) & 79.72 & 75.80 & 72.70 & 76.60 & 80.95 \\
\hline Degree of Esterification (\%) & 68.74 & 42.80 & 39.48 & 74.64 & 41.72 \\
\hline
\end{tabular}

\section{CONCLUSION}

In the present study, pectin extracted from the various sources was found to possess all physical and chemical characteristics ideal to be used for commercial purpose. It was also observed that pectin extracted from sources which are commonly used for commercial purpose was superior as compared to the unconventional sources like carrot and french bean. But in view of easy availability and relative low-cost, these sources can be considered as cheap alternative source of pectin particularly when food additives from natural sources are preferred to avoid health hazards associated with synthetic additives. 


\section{REFERENCES}

1. Kanmani P, Dhivya E, Arvind J, Kumaresan K, Preparation of samples for pectin extraction and isolation of pectin from different sources, Iranica Journal of Energy and Environment, 5(3), 2014, 303-312.

2. Smith DA, Jams and Preserves, Methods of Manufacture" in Encyclopedia of Food Sciences and Nutrition (Second Edition), Academic Press, 2003, pp. 3409-3415.

3. Azad AKM., Ali MA,] Akter S, Rahman J, Ahmed M, Isolation $\&$ characterization of pectin extracted from lemon pomace during ripening, Journal of Food and Nutrition Sciences, 2(2), 2014, 30-35.

4. Tang PY, Kek TS, Gan CZ, Hee CY, Chong CH, Woo KK., Yield and some chemical properties of pectin extracted from the peels of dragon fruit [Hylocereus polyrhizus (Weber) Britton, The Phillipine Agricultural Sciences, 94(3), 2011, 307-311.

5. Flutto L, PECTIN | Properties and Determination, in Encyclopedia of Food Sciences and Nutrition (Second Edition)", Academic Press, 2003, pp. 4440-4449.

6. May $C D$, Industrial Pectins: Sources, Production and Applications, Carbohydrate Polymers, 12( 3), 1990 , 79-99.

7. Sharma PC, Gupta A,Kaushal P, Optimization of method for extraction of pectin from apple pomace, Indian Journal of Natural Products and Resources 5(2), 2014, 184-189.

8. Sood N, Mathur A, Evaluation of Pharmacological Activities of Pectin extracted from Apple and Citrus pomace, Biolife, 2( 4), 2014,1203-1217.

9. H.K. Sharma HK, Lahkar S, Nath LK, Extraction, Characterisation and Compatibility Study of Polysaccharides from Dillenia indica and Abelmoschus Esculentus with Metformin Hydrochloride for Development of Drug Delivery System, Int. J. PharmTech Res.,5(1), 2013, 275-283.

10. Ranganna $S$, "Handbook of Analysis and Quality Control of Fruit and Vegetable Products( $2^{\text {nd }}$ Ed. ), New Delhi: McGraw Hill publishing Co. Ltd., 1995, 33-43.

11. AOAC, Official Methods of Analysis, vol. 37., 16 th ed. Association of Official Analytical Chemists, Washington, 1995, 1-10
12. AOAC, Official Methods of Analysis. Association of Official Analytical Chemistry, Washington DC., 1975, 450-451, 520521.

13. Fishman ML, Pfeffer PE, Barford RA, Done LW, Studies of pectin solution properties by High performance exclusion Chromatography, Journal of Agriculture and Food chemistry, 32(2), 1984, 372-378.

14. Abdul DA, Preparation and characterization of Pectin from peel of Kabad (Citrus Medica) fruit in Sulaimani City, Iraqi Kurdistan region, International Journal of Current Research in Chemistry and Pharmaceutical Sciences, 1 (7), 2014, 142146.

15. Khan M,Bibi N ,Zeb A, Optimization of Process Conditions for Pectin Extraction from Citrus Peel, Sci. Technol. Dev., 34 (1), 2015, 9-15.

16. Jafari F, Khodaiyan F, Kiani $\mathrm{H}$, Hosseini SS, Pectin from carrot pomace: Optimization of extraction and physicochemical properties, Carbohydrate Polymers, 157, 2017, 1315-1322.

17. Constenla $D$ and Lozano JE, Kinetic model of pectin demethylation, Latin American Applied Research, 33(2), 2003, 91-96.

18. Altaf $\mathrm{U}$, Immanuel $\mathrm{G}$, Iftikhar $\mathrm{F}$, Extraction and characterization of pectin derived from papaya (Carica Papaya Linn.) peel, International Journal of Science, Engineering and Technology 3(4); 2015, 970-974.

19. Mellinas C, Ramos M, Jiméne A, Garrigós MC, Recent Trends in the Use of Pectin from Agro-Waste Residues as a NaturalBased Biopolymer for Food Packaging Applications, Materials, 13(3), 2020, 673.

20. Sundar Raj AA, Rubila $S$, Jayabalan R, Ranganathan TV,A review on pectin: Chemistry due to general properties of pectin and pharmaceutical uses. Scientific reports, 1(2) 2012, 1-4.

21. Virk BS, Sogi DS,Extraction and Characterization of Pectin from Apple (MalusPumila. CV Amri) Peel Waste, International Journal of Food Properties, 7(3), 2004, 693703.

22. P. Khamsucharit P, K. Laohaphatanalert K, P. Gavinlertvatana $P$, K. Sriroth K, K.Sangseethong K, Characterization of pectin extracted from banana peels of different varieties, Food Sci Biotechnol, 27(3), 2018,623-629.

Source of Support: None declared.

Conflict of Interest: None declared.

For any question relates to this article, please reach us at: editor@globalresearchonline.net New manuscripts for publication can be submitted at: submit@globalresearchonline.net and submit_ijpsrr@rediffmail.com 